\title{
New chlorin e6 amide derivatives with fragments of 1,3-diaminopropane
}

\author{
C) Lyudmila A. Tulaeva, ${ }^{1+}$ Irina A. Morozova, ${ }^{1}$ and Dmitry V. Belykh ${ }^{2 *}$ \\ ${ }^{1}$ Department of Chemistry. Institute of Natural Sciences. Syktyvkar State University. \\ OrktyabrskyAve., 55.Syktyvkar,167000.Russia.E-mail: tulaeva65@mail.ru \\ ${ }^{2}$ Laboratory of Organic Synthesis and Chemistry of Natural Compounds. Institute of Chemistry, \\ Komi Scientific Center. Ural Branch. Russian Academy of Sciences. Pervomayskaya St., 48. \\ Syktyvkar, 167000.Russia.E-mail: belykh-dv@mail.ru
}

\begin{abstract}
*Supervising author; ${ }^{+}$Corresponding author
Keywords: methylpheophorbide $a, 1.3$-diaminopropane, amide derivatives of chlorin $\mathrm{e}_{6}$.
\end{abstract}

\begin{abstract}
In this work, we studied the interaction of methylpheophorbide $a$ with 1,3-diaminopropane and proposed a simple method for the synthesis of chlorin $\mathrm{e}_{6}$ derivatives with one, two, and three amino groups on the periphery of the macrocycle. It is shown that, when methylpheophorbide $a$ acts on 1,3-diaminopropane in a medium of chloroform or methylene chloride, the exocycle opens chemically selectively and chlorin $\mathrm{e}_{6} 13-$ amide derivative of with an amino group attached by a spacer of three methylene groups forms (chlorin $\mathrm{e}_{6} 13-$ $N$-(3-aminopropyl)amide 15,17-dimethyl ether). By the action of 1,3-diaminopropane on chlorin $\mathrm{e}_{6} 13-\mathrm{N}-(3-$ aminopropyl)amide 15,17-dimethyl ether at room temperature without solvent, chlorin $\mathrm{e}_{6} 13,17-N, N^{\prime}-(3-$ aminopropyl) can be chemically selective diamide 15-methyl ether and chlorin $\mathrm{e}_{6} 13,17-N, N^{\prime}, N^{\prime \prime}-(3-$ aminopropyl)triamide with two and three amino groups, respectively. The preparation of di- and triaminochlorins can be carried out both from chlorin $\mathrm{e}_{6} 13-\mathrm{N}$-(3-aminopropyl)amide of 15,17-dimethyl ether, and directly from methylpheophorbide $a$ without isolation of the intermediate monoaminochlorin. In the latter case, after the methylpheophorbide $a$ exocycle is opened with 1,3-diaminopropane in chloroform or methylene chloride medium, the solvent is distilled off from the reaction mixture and the resulting monoaminochlorin reacts with the 1,3-diaminopropane present in the mixture without solvent. The structure of the obtained mono-, di, and triaminochlorins is confirmed by IR and NMR spectroscopy.
\end{abstract}

\section{References}

[1] Muhammad Imran, Muhammad Ramzan, Ahmad Kaleem Qureshi, Muhammad Azhar Khan 2 and Muhammad Tariq. Emerging Applications of Porphyrins and Metalloporphyrins in Biomedicine and Diagnostic Magnetic Resonance Imaging. Biosensors. 2018. Vol.8. No.4. P.95. doi:10.3390/bios8040095.

[2] Heidi Abrahamse, Michael R. Hamblin. New photosensitizers for photodynamic therapy. Biochem. J. 2016. Vol.473. P.347-364. doi:10.1042/BJ20150942.

[3] Demian van Straten, Vida Mashayekhi, Henriette S. de Bruijn, Sabrina Oliveira and Dominic J. Robinson. Oncologic Photodynamic Therapy: Basic Principles, Current Clinical Status and Future Directions. Cancers. 2017. Vol.9. No.2. P.19. doi:10.3390/cancers9020019.

[4] D.V. Belykh. C-O, C-S, C-N, and C-C Bond Formation at the Periphery of the Macrocycle during Chemical Modifi cation of Phytochlorins: Key Methods and Synthetic Applications. Russian Journal of General Chemistry. 2019. Vol.89. No.12. P.2604-2649.

[5] M.V. Mal'shakova, D.V. Belykh, A.V. Kuchin. Synthesis of chlorins with a distal vinyl group. Chemistry of Natural Compounds. 2007. Vol.43. No.2. P.197-200.

[6] A.Yu. Rybkin, A.Yu. Belik, N.S. Goryachev, P.A. Mikhaylov, O.A. Kraevaya, N.V. Filatova, I.I. Parkhomenko, A.S. Peregudov, A.A. Terent'ev, E.A. Larkina, A.F. Mironov, P.A. Troshin, A.I. Kotelnikov. Self-assembling nanostructures of water-soluble fullerene[60]-chlorin e6 dyads: Synthesis, photophysical properties, and photodynamic activity. Dyes and Pigments. 2020. Vol.180. P.108411.

[7] Marina V. Mal'shakova, Yana I. Pylina, Dmitry V. Belykh. Novel hydrophilic galactose-conjugated chlorin e6 derivatives for photodynamic therapy and fluorescence imaging. Bioorganic \& Medicinal Chemistry Letters. 2019. Vol.29. P.2064-2069. 
[8] D.V. Belykh, M.V. Malshakova, A.V. Kletskov, E.S. Ivanova, Y.V. Dutikova, V.I. Potkin, and A.A. Shtil. Cytotoxic Chlorin e6 Derivatives with One or Two 4,5-Dichloro-1,2-thiazole Fragments Macroheterocycles. 2018. No.11(3). P.269-272. doi: 10.6060/mhc170726b

[9] D.V. Belykh, M.V. Malshakova. Dimerization of pheophorbide $a$ with activated carboxylic group in the reaction with ethylenediamine. Russian Journal of General Chemistry. 2018. Vol.88. No.6. P.1133-1137. DOI: $10.1134 / \mathrm{S} 1070363218060142$

[10] Alexander V. Nyucheva, Vasiliy F. Otvagina, Andrei E. Gavryushinb, Yuliya I. Romanenkoc, Oscar I. Koifmanc, Dmitrii V. Belykhd, Hans-Günther Schmalze, Alexey Yu. Fedorov. Synthesis of Chlorin(Arylamino)quinazoline Hybrids as Models for Multifunctional Drug Development. Synthesis. 2015. Vol.47. No.23. P.3717-3726.

[11] M.V. Mal'shakova, Y.I. Pylina, L.L. Frolova, J.H. Alekseev, S.A. Patov, D.M. Shadrin, A.V. Kuchin, I.O. Velegzhaninov and D.V. Belykh. New Chlorin-Terpene Conjugates: Synthesis, Photoinduced and Dark Cytotoxicity. Macroheterocycles. 2016. Vol.9. No.3. P.238-243. doi: 10.6060/mhc160753b

[12] Vladimir A. Zolottsev, Olga V. Zazulina, Galina E. Morozevich, Maria G. Zavialova, Alexander Y. Misharin, Roman A. Novikov, Vladimir P. Timofeev, Oskar I. Koifman,c and Gelii V. Ponomarev. Conjugates of Pyropheophorbide a with Androgen Receptor Ligands. Macroheterocycles. 2017. Vol.10. No.1. P.77-80. doi: $10.6060 / \mathrm{mhc} 160857 \mathrm{p}$

[13] A.V. Kuchin, V.A. Ol'shevskaya, M.V. Mal'shakova, D.V. Belykh, P.V. Petrovskii, O.G. Ivanov, A.A. Shtil', and V.N. Kalinin. New carborane derivatives of chlorin $\mathrm{e}_{6}$. Doklady Chemistry. 2006. Vol.409. Part 2. P.135-138. doi:10.1134/S0012500806080039

[14] Valentina A. Ol'shevskaya, Roza G. Nikitina, Arina N. Savchenko, Marina V. Malshakova, Alexander M. Vinogradov, Galina V. Golovina, Dmitry V. Belykh, Alexander V. Kutchin, Mikhail A. Kaplan, Valery N. Kalinin, Vladimir A. Kuzmin, Alexander A. Shtil. Novel boronated chlorin e6-based photosensitizers: Synthesis, binding to albumin and antitumour efficacy. Bioorganic \& Medicinal Chemistry. 2009. Vol.17. P.1297-1306. doi:10.1016/j.bmc.2008.12.016

[15] M.V. Kuchin, M.V. Mal'shakova, D.V. Belykh, V.A. Ol'shevskaya, V.N. Kalinin. Doklady Chemistry. 2009. Vol.425. No.6. P.87-90.

[16] D.V. Belykh, M.V. Malrshakova, Yu.A. Yudina, K.A. Zavadskaya, V.M. Khudyaev, A.V. Kuchin. Synthesis of potential antitumor agents, dimeric and trimeric chlorins, from methylpheophorbide $a$. Russian Chemical Bulletin, International Edition. 2011. Vol.60. No.4. P.719-728.

[17] D.V. Belykh, M.V. Mal'shakova, Yu.A. Yudina, K.A. Zavadskaya, V.M. Khudyaev, and A.V. Kuchin. Synthesis of potential antitumor agents, dimeric and trimeric chlorins, from methylpheophorbide $a$. Russian Chemical Bulletin, International Edition. 2011. Vol.60. No.4. P.719-728.

[18] D.V. Belykh, M.V. Malshakova, M.G. Korochkina, V.E. Kataev, and A.V. Kuchin. First macrocycle based on chlorin and isosteviol structural elements. Chemistry of Natural Compounds. 2011. Vol.47. No.4. P.612-614.

[19] Kevin M. Smith, Dane A. Goff, Daniel J. Simpson. Meso Substitution of Chlorophyll Derivatives: Direct Route for Transformation of Bacteriopheophorbides d into Bacteriopheophorbides c. J. Am. Chem. SOC. 1985. Vol.107. No.17. P.4946-4954.

[20] D.V. Belykh, and M.V. Mal'shakova. Interaction of methylpheophorbide (a) with ethylenediamine. Butlerov Communications. 2014. Vol.39. No.10. P.35-42. ROI-jbc-02/14-39-10-35

[21] D.V. Belykh, E.A. Kopylov, I.V. Gruzdev, A.V. Kuchin. Opening of the Extra Ring in Pheophorbide a Methyl Ester by the Action of Amines as a One-Step Method for Introduction of Additional Fragments at the Periphery of Chlorin Macroring. Russian Journal of Organic Chemistry. 2010. Vol.46. No.4. P.577-585. 